\title{
Comunidades de mulheres ceramistas e a longa trajetória de itinerância da cerâmica paulista
}

\author{
Francisco Silva Noelli* \\ Marianne Sallum* *
}

NOELLI, F.S.; SALLUM, M. Comunidades de mulheres ceramistas e a longa trajetória de itinerância da Cerâmica Paulista. R. Museu Arq. Etn. 34: 132-153, 2020.

Resumo: A Cerâmica Paulista resultou da conexão de tecnologias, práticas, significados e memórias. Ela foi produzida inicialmente pelas tupiniquins, em uma aliança com os portugueses na área de São Vicente e continuada por diversas gerações de mulheres, incluindo as que vieram de fora. No contexto dessas relações, materialidades e alimentos foram usados, apropriados e transformados, através de escolhas que entrelaçaram tecnologias antigas com novidades e mudanças culturais e identitárias. $\mathrm{O}$ exame de vasilhas inteiras, de fragmentos e dados publicados, mostra que a Cerâmica Paulista foi produzida desde o século XVI com algumas variações. A persistência das comunidades de práticas levou adiante maneiras de fazer e usar vasilhas cerâmicas, moldando valores e relações sociais que definiram a identidade Paulista.

Palavras-chave: Arqueologia; Cerâmica colonial; Gênero; Tupi; Colonialismo.

Evidência de ausência não é ausência de evidência. Carl Sagan, 1995: 213.

- $\mathrm{ste}$ artigo propõe o conceito para

Cum conjunto de vasilhas cerâmicas produzidas desde o século XVI. É uma perspectiva dedicada a compreender a história da relação entre pessoas e objetos em seu contexto social. A produção começou com as Tupiniquim,

* Doutorando em Arqueologia e Pesquisador no Centro de Arqueologia da Universidade de Lisboa (Uniarq), Portugal. <francisconoelli@edu.ulisboa.pt>

"Pós-doutoranda do Laboratório Interdisciplinar de Pesquisas em Evolução, Cultura e Meio Ambiente (Levoc) do Museu de Arqueologia e Etnologia da Universidade de São Paulo (MAE-USP), Brasil. Pesquisadora no Centro de Arqueologia da Universidade de Lisboa (Uniarq), Portugal. <marisallum@usp.br> continuou com as suas descendentes com os portugueses e com pessoas que vieram de fora, todas referidas desde o século XVII como as de "São Paulo" e "Paulistas". Nesse sentido, a cerâmica é paulista e, por isso, não a definimos como "Cerâmica Tupiniquim". Foi o resultado da conexão de antigas e novas práticas com "construções estratégicas da memória e do esquecimento" (Hayes 2011), de onde emergiram gradativamente identidades descobertas na superação do pluralismo que dividia os coletivos. Seriam casos de deslocamento identitário, quando as pessoas faziam e refaziam frequentemente suas relações e noções de pertencimento, diferentemente da "ideia totalizante de uma sociedade nacional integrada $[. .$.$] que depende da guerra constante$ contra as diferenças" (Goldman 2017: 10). 
Não encontramos ainda fontes escritas e relatos sobre nomes que as ceramistas davam ao seu conjunto vasilhas, pois elas nomeavam apenas objetos específicos em relação a sua função. Portanto, sugerimos um conceito para representar o conjunto das cerâmicas produzidas em lugares e tempos diferentes, por comunidades que compartilharam conhecimentos tecnológicos e percepções sensoriais que entrelaçam a memória das gerações do presente com passados coletivos e concretos (Hamilakis 2013). Assim, definimos Cerâmica Paulista como a "cerâmica comum portuguesa apropriada e transformada no século XVI pelas Tupiniquim da área de São Vicente para uso nos assentamentos coloniais e reproduzida até o presente na região sudeste de São Paulo" (Noelli \& Sallum 2019: 703). Essa definição foi embasada no registro arqueológico das vasilhas escavadas em Peruíbe, na bibliografia, coleções de museus e na nossa perspectiva do processo colonial. A cerâmica foi produto da relação e troca de conhecimentos e tecnologias num contexto particular que levou à formação dos primeiros núcleos coloniais, na área entre os assentamentos entre São Vicente e Itanhaém. O registro arqueológico da Cerâmica Paulista indica que ela foi produzida nos sítios fundados nos séculos XVI e XVII na atual região metropolitana de São Paulo, depois acompanhou a conquista do Rio de Janeiro, o ciclo da mineração no Vale da Ribeira e no nordeste do Paraná. Depois, a descida para o sul de Guaratuba, em alguns sítios entre São Francisco do Sul e Laguna, e acompanhou a expedições escravagistas no interior do Paraná, Minas Gerais, Mato Grosso e Goiás, indicando que havia presença de mulheres nessas campanhas. As fontes mostram que a cerâmica serviu primeiro ao uso familiar e eventos comunitários, sugerindo que o início da comercialização foi apenas no final do século XVII ou começo do XVIII, quando as diferenças entre os assentamentos ficaram mais marcadas, distinguindo-se as comunidades agroflorestais dos núcleos urbanos que recebem imigrantes europeus e das plantations com mão de obra de africanos escravizados. Desde meados do século XX a maioria da produção foi destinada ao comércio, passando a cerâmica a ser consumida também como artesanato.

Não consideramos a Cerâmica Paulista pela perspectiva dos modelos evolucionistas e difusionistas (Jones, 1997), nem como processo de mestiçagem ou criolização. A percebemos como resultado da conexão de ontologias, como "encontros e articulações possivieis entre os lados do mundo que, ao mesmo tempo, sempre preservam a diferença” (Pazzarelli et. al. 2017: 9). Ela foi uma criação das Tupiniquim que, apesar de terem mudado a sua cerâmica pré-colonial e estabelecido de uma relação de aliança com os portugueses, mantiveram a sua identidade. Já as suas descendentes com os portugueses praticavam uma espécie de "jogo de identidade", que as aproximavam ou distanciavam dos Tupiniquim ou portugueses dependendo das circunstâncias (Monteiro 2001:9). Enquanto isso, as práticas e conhecimentos eram transmitidos às futuras gerações, cuja persistência resultou de: (1) consumo integrado ao estilo de vida agroflorestal autodeterminado e autossustentado na Mata Atlântica; e (2) renovada decisão de manter a cerâmica, porém incorporando elementos decorativos, transmitindo conhecimentos entre as gerações. A persistência não é aqui sinônimo de continuidade histórica e nem da passagem do tempo, mas da articulação "intencional de certas práticas e identidades relativas à luz de novas economias, políticas e realidades sociais [...] unindo efetivamente passado e presente numa dinâmica e inquebrável trajetória"

(Panich et al. 2018: 11-12). A percepção disso depende da compreensão das relações entre conhecimentos de lugares e tempos diferentes, das "escalas temporais e analíticas que equilibrem tanto a dizimação e a celebração da mistura (curto prazo), quanto as histórias mais profundas (longo prazo), que informam as ações das pessoas e se estendem além dos períodos de mistura" (Silliman, 2015: 291-292).

A Cerâmica Paulista precisa ser compreendida tanto nos diversos contextos 
onde foi produzida, quanto naqueles onde foi consumida e adquiriu novos significados por diversas pessoas de diferentes estratos sociais (Sallum \& Noelli, 2020), considerando que a sua persistência engloba "mudanças dentro de continuidades e continuidades dentro de mudanças" (Silliman 2020: 67-68). Ela teria resultado de "manifestações legítimas de modos específicos de se produzir e utilizar substâncias, matériasprimas e objetos segundo lógicas de classificação e transformação específicas" (Lagrou 2013: 22). E teria prosperado pela agência e escolha pragmática das mulheres para "resistir, acomodar ou evitar várias imposições coloniais" (Panich 2020: 9), onde apropriação e transformação não equivalem à perda cultural (Sallum 2018), mas ao "paradigma da troca", onde:

o evento de troca é sempre a transformação de um evento de troca anterior. Não há um começo absoluto, sem um ato de troca absolutamente inicial. Cada a to é uma resposta, isto é, a transformação de uma lembrança anterior do mesmo tipo (Viveiros de Castro 2004: 477).

\section{A persistência da Cerâmica Paulista tem} uma itinerância. Da perspectiva da arqueologia, a noção de "itinerário dos objetos" expressa a sua "vida ativa antes, durante e depois das interações com humanos" (Joyce \& Gillespie 2015).

A consideração de que os objetos possuem itinerância leva à percepção da "continuidade da mudança de significados e associações para cada categoria de objetos", e ao reconhecimento de que os "objetos possuem interações sociais com humanos", sendo "um importante aspecto para desenvolver uma compreensão melhor de como objetos podem moldar os humanos, mas também de como os humanos podem moldar os objetos" (Sheridan 2018). No caso da Cerâmica Paulista e da sua linguagem, a itinerância começa com a adoção da tecnologia portuguesa, transformada pelas Tupiniquim em uma cerâmica sua. Com o passar do tempo continuou sendo produzida e usada pelas descendentes e pessoas vindas de fora. No século 18 , algumas mulheres começaram a produzir para um comercio urbano em crescimento, que ainda era uma economia de troca. Mais tarde, a monetização substituiu as práticas de intercâmbio, mas a produção de cerâmica continuou a ser uma atividade familiar que ocorria em pequenas comunidades de mulheres ceramistas. Nas últimas cinco décadas (Magrini, 2019), a cerâmica seguiu várias trajetórias nessas comunidades: 1) a produção diminuiu devido à falta de estímulo para fazê-los, com poucos lares ainda usando vasos de cerâmica para alimentos específicos; 2) as cooperativas de cerâmica e o crescente mercado de "artesanato" foram alternativas à continuidade da produção e autonomia das mulheres, integrando atributos antigos e novos, e incorporando os homens no processo de produção (Sallum \& Noelli, no prelo).

A linguagem teve igualmente uma itinerância. Afinal, o "português" falado em São Paulo também foi apropriado e transformado, não sendo mais aquele de Portugal. E a língua Tupiniquim incorporada pelos portugueses e outros que vieram de fora, incluindo indígenas escravizados (principalmente os Guarani), europeus e africanos, resultou na Língua Geral Paulista (LGP), falada até o século XIX (Leite 2013). O dialeto "caipira" foi uma deriva da LGP, a partir de meados do século XVIII. Este período foi marcado pela transformação linguística de São Paulo, em parte pelas mudanças demográficas resumidas abaixo, em parte pela força coercitiva do poder português instrumentalizado pelas lei pombalinas, que só teve efeito por causa: (1) da crise demográfica Tupiniquim; (2) da política de apagamento dos etnônimos na documentação burocrática; (3) do esforço em eliminar as diferenças de identidade entre os povos indígenas; e (4) dos "jogos de identidade" (Monteiro 2001). Contudo, a linguagem da Cerâmica Paulista ainda guarda no presente termos Tupiniquim.

Também houve uma itinerância acadêmica. Essa cerâmica foi originalmente definida em uma perspectiva etnográfica, por Herta Löel Scheuer (1976), como "cerâmica popular de São Paulo". O seu levantamento de campo foi bastante completo e ofereceu dados sobre as mulheres, processos de transmissão de 
conhecimentos e o seu contexto de produção, assim como o uso da cerâmica em oito comunidades paulistas. Também fez um inventário da memória genealógica, retrocedendo até a década de 1850, mas não investigou a história para alcançar um período mais recuado ou identificar contextos sociais de produção do passado. O mais importante é que Scheuer evidenciou a estrutura que modelava o espaço e a prática das mulheres, replicada nas comunidades que investigou, sobretudo no sudeste de São Paulo e nordeste do Paraná. Era um tema inteiramente desconhecido da academia naquele momento, muito embora as suas cerâmicas já fossem comercializadas como artesanato e colecionadas em alguns museus de São Paulo. O fato é que antes de iniciar este projeto (Sallum 2018), não era conhecida a longa trajetória dessa cerâmica em direção ao passado, até as Tupiniquim.

A demografia sugere um contexto peculiar no sudeste de São Paulo em relação aos itinerários da cerâmica, pois ao longo do processo histórico a configuração sociocultural da sociedade paulista mudou gradativamente (Sallum \& Noelli 2020). A região teve um processo social que iniciou com maioria demográfica Tupiniquim e poucos portugueses, do início do século XVI a meados do século XVII. A população Tupiniquim foi diminuindo, enquanto seus descendentes com os portugueses, tinham quantitativamente maior tamanho no final do século XVII, com os portugueses continuando minoria. No século XVIII, os Tupiniquim deixam de ser mencionados na burocracia, enquanto os descendentes sobressaem, junto com uma crescente população portuguesa imigrada ao Brasil devido ao ciclo do ouro em Minas Gerais. Nos séculos XIX e XX, começam a vir brasileiros de outras regiões do país, mais europeus asiáticos e grupos falantes do Guarani.

$\mathrm{O}$ ingresso de escravos indígenas, sobretudo dos Guarani da região sul, do Mato Grosso do Sul e do Paraguai, foi constante desde a primeira metade do século XVI até a década de 1670 .

A escravidão de africanos e de afrodescendentes ganhou impulso a partir de 1700 , mas sem uma quantidade expressiva no sudeste, formando, por exemplo, pequenos núcleos no litoral, entre Peruíbe e Cananéia, que produziram vasilhas diferentes da Cerâmica Paulista. Também produziram uma cerâmica distinta da paulista no litoral norte (Agostini 2010) e partes vizinhas do interior (Morales 2001).

\section{Fundamentos para definir a Cerâmica Paulista}

Não consideramos a Cerâmica Paulista como uma cultura material estática. Em vez disso, buscamos outras perspectivas centradas na apropriação de objetos estrangeiros: (1) o "conceito de incorporação da alteridade" e "uma máquina de produção de sentimentos com uma estética viva, não congelada", desenvolvido por Els Lagrou (2016: 13); (2) a Arqueologia da Persistência (Silliman 2009). Ambos os termos problematizam conceitos como "aculturação", "hibridismo" e "inautenticidade", mostrando que alguns ameríndios no Brasil e os Pequot Orientais nos Estados Unidos não se tornaram menos indígenas, nem criaram materialidades mistas quando se apropriaram de tecnologias dos outros. Estamos à procura de uma explicação abrangente para a longa trajetória das comunidades de ceramistas.

A Cerâmica Paulista não foi cópia de tipos de vasilhas, nem adoção automática de tecnologia. Ela não foi a união de conjuntos "tupiniquins" e "portugueses" preexistentes, mas a articulação de alteridades regida por princípios relacionais materiais e cosmológicos. De um lado estava a predação como exercício da alteridade Tupi (Ribeiro \& Jácome 2014), da incorporação do outro escolhido por afinidades como meio de uma construção social constantemente atualizada (Viveiros de Castro 1992). De outro lado, temos as estratégias individuais e estatais dos portugueses, visando estabelecer uma sociedade que funcionasse para eles. Um dos representantes dos interesses da Coroa deixou claro que as lideranças portuguesas queriam eficiência no processo colonial: em 1532, Pero Lopes de Sousa (1994: 184) destacou a importância dos portugueses "viverem em comunicação das artes" com os indígenas, referindo-se, pois, à "troca de práticas" para compreender o modo de viver 
Comunidades de mulheres ceramistas e a longa trajetória de itinerância da cerâmica paulista

R. Museu Arq. Etn., 34: 132-153, 2020.

Tupiniquim. Mas parece evidente que foi a ação de engajamento individual, descentralizada e fora da hierarquia, que foi a chave para o desenvolvimento da relação, pois foi entre pessoas que as alteridades se consolidaram e não entre lideranças de entidades homogêneas.

Nesse contexto, o desenho das vasilhas parece ter sido das mulheres Tupiniquim a partir dos seus conhecimentos tecnológicos para decidir e escolher morfologias e atributos indígenas e europeus. Exemplo disso foi a não adoção de elementos centrais da cadeia operatória da cerâmica comum portuguesa: o torno ou roda de oleiro e, consequentemente, a técnica corporal para usá-lo, vasilhas com determinadas morfologias e decorações decorrentes do emprego do torno. A falta de adaptação não seria uma das explicações da rejeição do torno em São Paulo, mas parece que a preferência parece vir da transmissão de conhecimentos aprendidos com as mulheres (Scheuer 1976: 7, 82). Ou seja, um habitus com práticas e performances intelectualmente escolhidos, replicados e transformados continuamente: (1) seleção de matérias-primas; (2) composição da pasta cerâmica; (3) técnica do acordelado para levantar a parede (Fig. 1); (4) temporalidade do processo construtivo da vasilha; e (5) modos de fazer o tratamento de superfície.

Ainda não podemos afirmar, mas o registro material evidencia a opção por manter o antiplástico de maior granulometria (eventualmente, acrescentava-se pó de fragmentos cerâmicos moídos ao tempero). Trata-se da replicação de uma escolha baseada no conhecimento tecnológico? Ou seria a composição natural das matérias-primas regionais, cujo ponto ideal da pasta e das suas características para a queima necessitavam tempero de maiores dimensões? Talvez as duas juntas. Nos parece que a decisão por um antiplástico com tais características tinha impacto direto na manutenção do acordelado e, consequentemente, na técnica corporal, pois essa granulometria não é adequada para o torno, dado que a sua fricção machucaria permanentemente as mãos, razão pela qual os portugueses usavam pasta com granulometria mais fina.

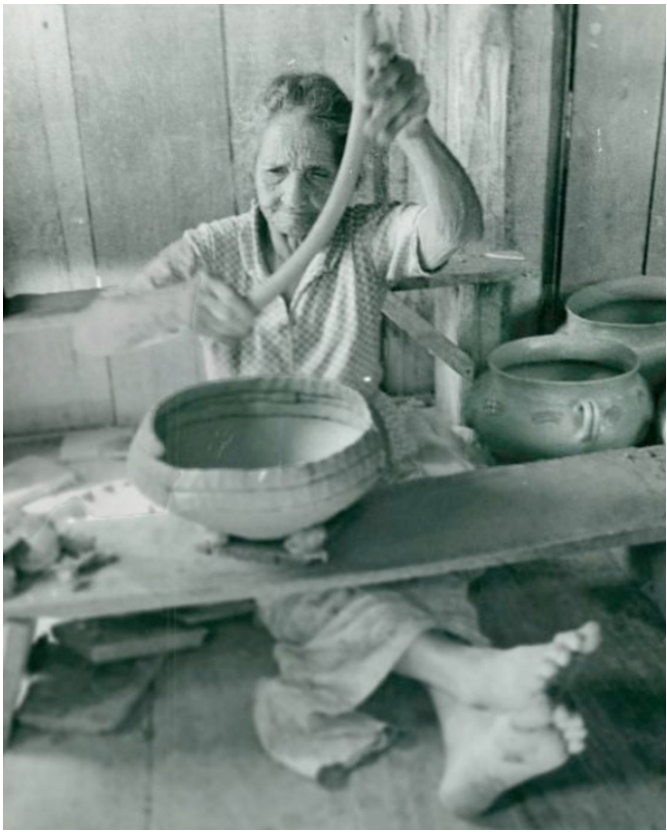

Fig. 1. Ceramista Ana Pereira (Jairê-Iguape). Foto Plácido de Campos Júnior, década de 1980.

Fonte: Museu de Imagem e do Som de São Paulo.

A dificuldade de adquirir a roda de oleiro não seria causa relevante, pois mesmo nas décadas de 1960 e 1980, as ceramistas evitavam incorporá-la, preferindo manter o acordelado (Scheuer 1976; Nascimento 1986), como fazem até o presente (Magrini 2019). Não há razão para considerar que a dificuldade de acesso ao equipamento importado fosse empecilho, pois as matérias-primas necessárias para fazê-lo estavam disponíveis já nos assentamentos coloniais, inclusive as partes metálicas, cujo volume seria menor que um machado de ferro. Se as mulheres quisessem a roda, tanto quanto os homens queriam machados e facas, certamente os portugueses também teriam providenciado tais objetos de troca. A produção para consumo doméstico sem fins comerciais poderia ser uma razão, cuja explicação será mais investigada e refinada futuramente neste projeto.

$O$ fato é que nos primeiros 50 anos os portugueses produziram sua olaria em São Paulo, tornando-a conhecida dos Tupiniquim. $\mathrm{O}$ uso e produção de alvenaria parece começar após 1520 , como sugere o manifesto de carga de um 
barco apreendido Europa em 1522 (Gosselain 1876: 38), transportando itens para construir um dos primeiros engenhos de açúcar no Brasil, talvez em São Vicente (Almeida Prado 1961: 279), incluindo mil tijolos para um moinho hidráulico que vinha desmontado a bordo. Por 1527-1530, já existiam casas de pedra com os seus "telhados" em São Vicente (Santa Cruz 1918: 517); em 1548 as edificações do engenho dos Erasmos eram telhadas (Anônimo 1968: 416) e, provavelmente, ali usavam torno para fazer vasilhas para fabricar açúcar e para uso doméstico; ao redor de 1550, havia telhas no forte de Bertioga (Jácome 1956: 246); em 1552, Itanhaém tinha "casas construídas à maneira dos cristãos" (Staden 1974: 70); em 1553, havia em São Vicente casas de "pedra e cal" (Sousa 1956: 484); em 1555, houve a proposta de contrato para fazer tijolos para duas pontes em Santos (Duarte da Costa 1956: 343). Anchieta (1958: 256) descreve em 1560 a autossuficiência da materialidade na comunidade masculina dos jesuitas que, entre várias produções, faziam "casas y cosas de barro", declarando que não compravam "cosas fora". Por fim, as primeiras licenças municipais conhecidas relacionadas ao uso de fornos de olaria que foram lavradas em São Paulo: (1) telhas, a 6 de março de 1575 (Câmara Municipal de São Paulo 1967: 67); e (2) "tijolo cozido de barro", a 23 de maio de 1610 (Câmara Municipal de São Paulo 1915: 268). Para o início do século XVII em São Paulo, há o registro de uma "fôrma de fazer louça", óbvia referência às técnicas portuguesas e ao domínio masculino (Brancante 1981: 210).

Ao mesmo tempo, havia o ingresso de vasilhas trazidas de Portugal e de outros países, usadas para o consumo de bordo, que muitas vezes eram mostradas aos indígenas no litoral brasileiro. Por exemplo, na sua carta de 1500, Pero Vaz de Caminha descreve como os indígenas foram servidos de vinho em uma taça e água de uma albarrada. Em 1522, na carga de um barco que vinha para o Brasil, apreendido na costa europeia, havia mais de 350 botijas com azeite de oliva e 25 arrobas de vinagre em botijas grandes (Gosselain 1876: 38-39). Elas também poderiam ser feitas localmente, por um oleiro português, nos assentamentos coloniais. De sorte que havia vasilhas europeias para servirem como inspiração às Tupiniquim. E aqui há uma questão importante: quais vasilhas portuguesas foram trazidas na primeira metade do século XVI e que serviram como inspiração para serem apropriadas pelas Tupiniquim?

Nos parece evidente que foram as cerâmicas comuns usadas em Portugal no final do século XV e início do XVI. Elas seriam uma opção surgida na convivência decorrente da relação e, consequentemente, do conhecimento e articulação de hábitos mútuos de consumo. Para alcançar plenamente essa demonstração, será importante desenvolver uma metodologia comparativa, estabelecendo uma base de dados tecnológicos e de consumo (incluindo aí a linguagem) para comparações entre os contextos português, Tupiniquim e paulista. Também é importante considerar o itinerário da Cerâmica Paulista e suas possíveis atualizações, uma vez que poderiam circular novidades tecnológicas ou de consumo (Fig. 2). Seria o caso, por exemplo, da "pichorra", o bule para café (Scheuer 1976: 64), equivalente, na linguagem portuguesa, da infusa, ou ainda jarra e pichel (Bugalhão \& Coelho 2017: 121; Fernandes 2012: 323-324). Como o café foi introduzido no Brasil no século XVIII, a função "bule para café" é a atualização de um tipo de vasilha produzida anteriormente para servir líquidos. Na década de 1960, Scheuer (1976: 6) verificou, comparando vasilhames "recentemente trabalhados com outros de mais de dez decênios, pode-se constatar uma continuidade nas formas. Exceto em alguns casos... não foram criadas formas estilísticas, mesmo ao surgirem cerâmicas com outras funções". 


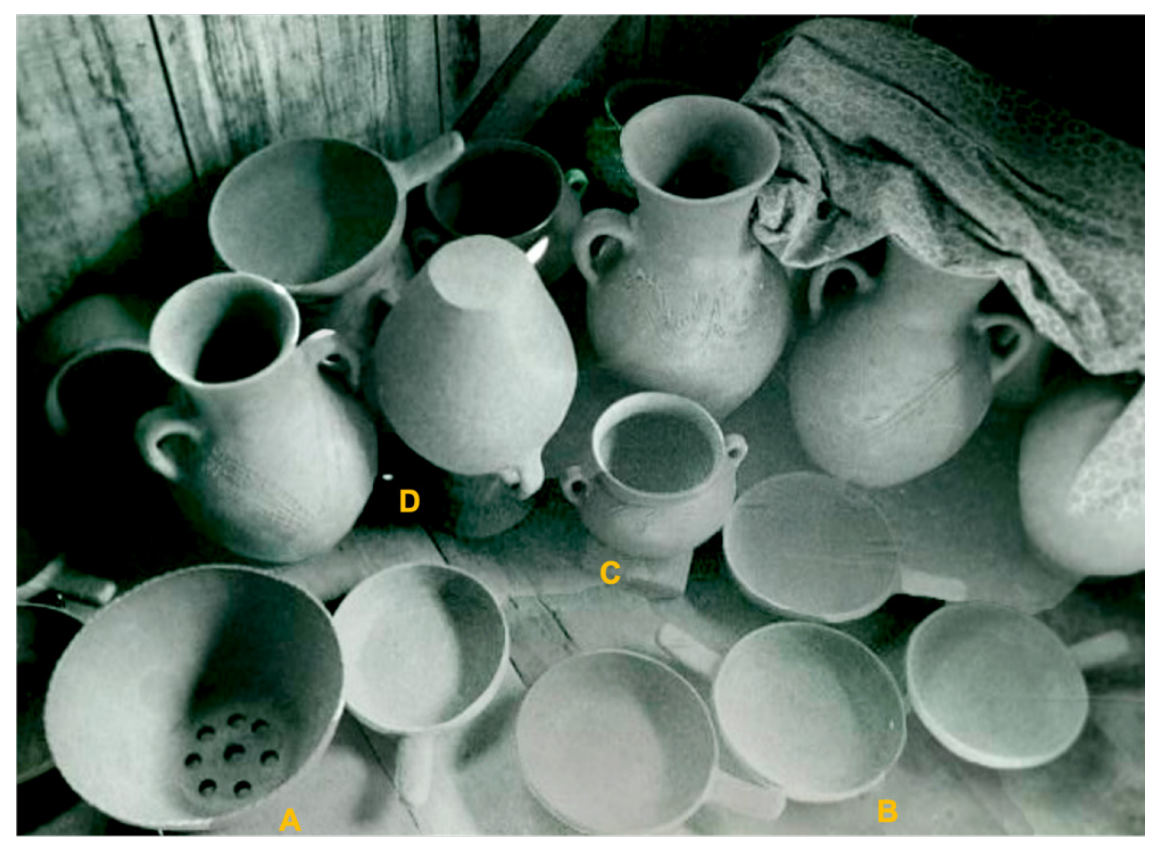

Fig. 2. Conjunto de vasilhas em secagem (Jairê-Iguape). A: cuscuzeiro; B: frigideira; C: panela; D: boião. Foto: Plácido de Campos Júnior, década de 1980.

Fonte: Museu de Imagem e do Som de São Paulo.

Por fim, é preciso considerar que na Capitania de São Vicente houve produções paralelas de cerâmicas comuns, incluindo a importação eventual. Não existem dados precisos, mas a demografia histórica sugere que a cerâmica comum portuguesa foi feita por homens nos núcleos coloniais e nas comunidades dos jesuítas, portanto feitas com o torno nos séculos XVI, XVII e XVIII eventualmente foram chamadas de "local/regional" por Zanettini (2005) e Zanettini \& Wichers (2009). As cerâmicas com estilo africano foram produzidas tardiamente, provavelmente a partir do século XVIII, quando aumentou o afluxo de escravos e libertos em razão da redução da quantidade de escravos indígenas e do crescimento do ciclo do ouro em Minas Gerais. Do século XVIII em diante, há dados históricos e demográficos a serem investigados, que permitem uma contextualização mais refinada em alguns locais, mas considerando a crescente diferenciação sociocultural, é evidente que a pesquisa sobre materialidade arqueológica precisa ser balizada pela história de cada localidade, a exemplo dos estudos de Morales (2001) em Jundiaí e de Agostini (2010) em São Sebastião. O censo de 1804 da cidade de São Paulo oferece pistas interessantes sobre os seus produtores de cerâmica, evidenciando ser uma atividade residencial e familiar (Rabello 1977). Dos 1667 fogos, em 160 havia "louceiros", dos quais 60 não eram escravizados, incluindo: 17 mulheres mulatas; 11 mulheres brancas; 23 homens mulatos; 9 homens brancos. O problema é descobrir quais tipos de cerâmica faziam (com ou sem torno) e, nos 100 fogos não referidos, se indígenas ou escravos africanos ou afro-brasileiros. Sabese que ao redor de 1800 , a cerâmica vendida na feira do Campo da Luz era produzida pelos "índios, que são os que fazem a louça ordinária" a ser usada pela "arraia-miúda" (Machado, 2013: 46). E, conforme Munsberg 
(2018: 97), as cerâmicas acordeladas e modeladas escavadas nos sítios "bandeiristas" da região metropolitana foram produzidas localmente entre os séculos XVII a XIX. Dependendo do sítio, as acordeladas compreendem de $53 \%$ a $100 \%$ das amostras escavadas, enquanto nos mesmos contextos as vasilhas torneadas e as industrializadas fora do Brasil são a menor quantidade.

\section{A produção da Cerâmica Paulista}

A seguir vamos comparar os processos de produção das cerâmicas Tupiniquim, portuguesa e paulista. Em outras publicações, com o avançar da pesquisa, apresentaremos o consumo e seus itens relacionados aos ciclos anuais de planejamento alimentar. As pesquisas etnográficas no sudeste de São Paulo deixaram claro que as exigências intelectuais das mulheres em relação à cerâmica se pautaram pelo "tenaz apego às formas tradicionais de nossas paneleiras [que] pode-se atribuir a uma motivação espiritual. Conscientes da tradição, permanecem fiéis a ela, transmitindo o saber da mesma maneira" (Scheuer 1976: 6). As ceramistas revelaram para Scheuer algo semelhante ao conceito de comunidades de práticas, resumido por Wendrich (2012) e que aborda as relações entre grupos e indivíduos, focando na aprendizagem individual e nas atividades grupais, onde o aprendizado é contínuo e baseado na troca de conhecimentos das experiências do grupo social, por razões e maneiras diferentes. Essas comunidades, para Wenger (1998), emergem pelo "engajamento mútuo, empreendimento conjunto e um repertório compartilhado", resultando da ação individual de participar se relacionando e criando conexões com outros e compartilhando histórias de aprendizado. Tais processos de identificação envolvem mutualidade, mas sem ser necessariamente de igualdade, podendo ser relações de conflituosas e competitivas ou cooperativas e harmoniosas (Roddick \& Stahl 2016).

Essas comunidades formam constelações de práticas, que vão para além de um ponto localizado, estando conectadas com outras comunidades e constelações de prática. As constelações são configurações muito amplas, diversificadas e "afastadas do escopo de engajamento dos participantes” de uma única comunidade de prática (Wenger 1998: 126-127). Elas estão conectadas de forma complexa e dinâmica, compartilhando raízes históricas através das ações e agência de seus participantes, explicando a persistência e a itinerância de cinco séculos da Cerâmica Paulista e, no período pré-colonial, de quinze séculos da cerâmica Tupiniquim. Assim, podemos concluir que não foi apenas a tecnologia que teve longa duração, pois ela existia devido as ações intencionais que fundamentavam os processos de compartilhamento e transmissão de conhecimentos nas comunidades de práticas.

Os processos de transformação tecnológica e uso pré-colonial para colonial não foram simultâneos entre todos os Tupiniquim, pois apenas alguns assentamentos indígenas estavam em relação com os portugueses. Estes passaram a produzir a Cerâmica Paulista na área de São Vicente, gradualmente ampliando a constelação de assentamentos coloniais em direção ao interior. Este processo foi uma forma de ampliar as redes de aprendizado e formação de novas comunidades de práticas, na área de circunscrição de São Paulo de Piratininga no século XVI. No século XVII, os assentamentos foram na direção sudeste de São Paulo e nordeste do Paraná, consolidando a formação de comunidades que existem até o presente, das quais algumas ainda produzem Cerâmica Paulista, como Apiaí, Itaoca e Iguape (Fig. 3). 


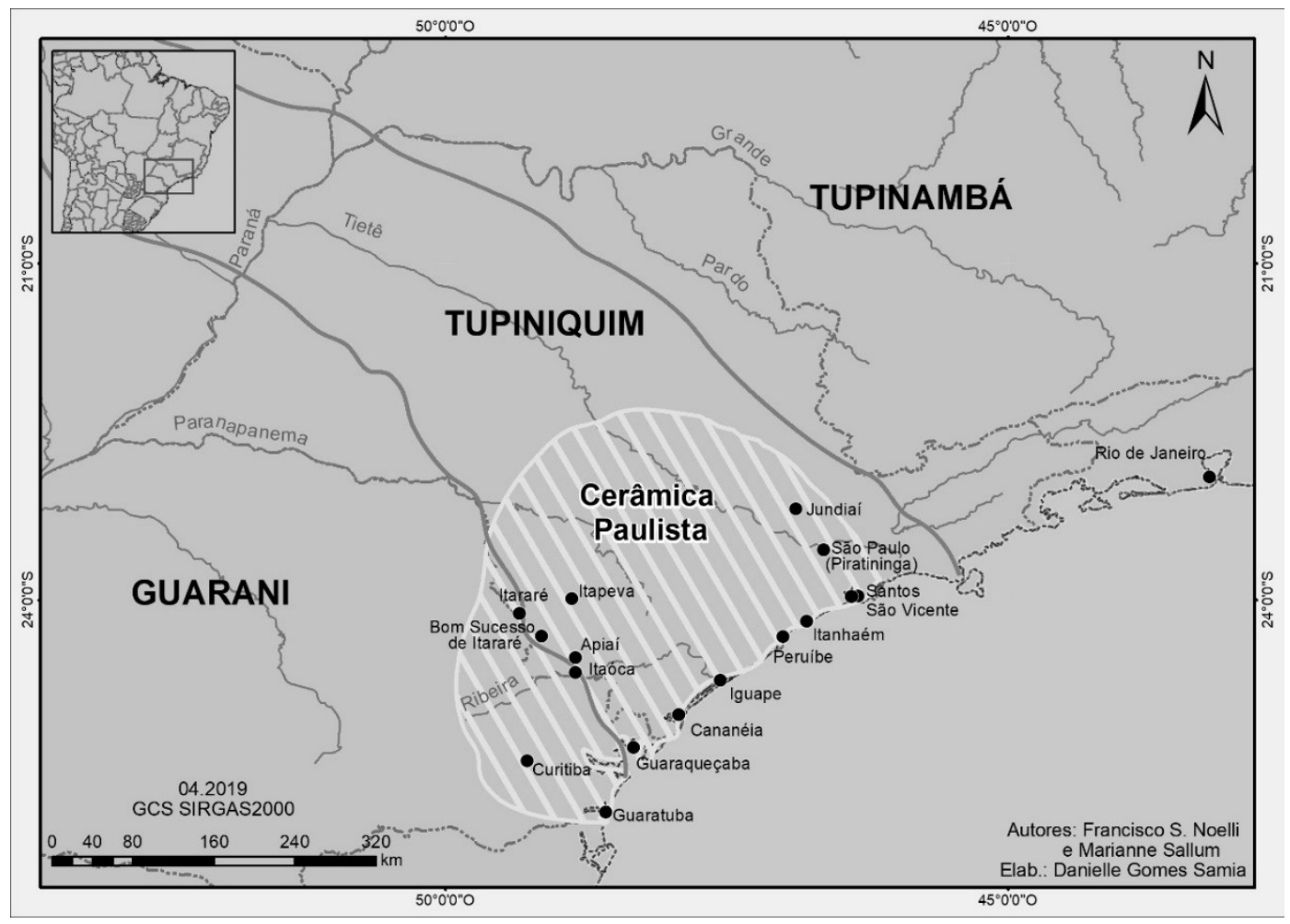

Fig. 3. Mapa de ocorrência da Cerâmica Paulista.

\section{A Cerâmica Paulista e seu contexto de produção}

Na divisão sexual do trabalho Tupiniquim, o gênero e a realização de tarefas eram polimórficos. As pessoas viviam uma lógica diferente dos padrões impostos pela moralidade colonial, que foi, geralmente, silenciada ou mal descrita, redundando em ignorância sobre as práticas e manifestações das mulheres indígenas. Enquanto a divisão de tarefas teve as suas características mantidas até o presente, a produção cerâmica foi domínio das mulheres, de suas descendentes e, posteriormente, das forasteiras integradas às redes de sociabilidades Tupiniquim no século XVI.

À primeira vista, a morfologia das cerâmicas pré-coloniais Tupiniquim tem poucas semelhanças com a cerâmica portuguesa e com a Cerâmica Paulista. Mas observando-se os detalhes, há similaridades na pasta, nos tratamentos de superfície, na seção do perfil da parede da vasilha, conjugando escolhas técnicas de dois modos oleiros, compreendendo: (1) relação e alteridade dos Tupiniquim e portuguesa; (2) apropriação de parte da tecnologia portuguesa pelas ceramistas indígenas; e (3) articulação de práticas cerâmicas com matérias-primas, cadeia operatória, linguagem e usos.

A comparação dos contextos de produção das cerâmicas será demonstrada a seguir, para mostrar alguns aspectos da via de mão dupla que mencionamos. O Quadro 1 resume os itens mais comuns entre os três contextos de produção, de acordo com os dados encontrados em fontes históricas, etnográficas e linguísticas. Para a demonstração ser objetiva, selecionamos nas sínteses mais completas os dados necessários para cumprir o nosso objetivo a seguir. Para as cerâmicas Tupiniquim, Corrêa (2014) oferece as informações sobre as vasilhas e a sua distribuição geográfica, compartilhadas com a cerâmica Tupinambá, pois ambas tinham 
padrões comuns de produção, uso e linguagem. O mapa da distribuição, o contexto de produção e a linguagem cerâmica comum portuguesa, especialmente a cerâmica preta, estão bem representados por Fernandes (2012) e Bugalhão \& Coelho (2017). Por fim, a Cerâmica Paulista tem seus contextos de produção, uso e linguagem descritos por Scheuer (1967, 1976, 1982), Nascimento (1986), Tiburtius (1968) e Sallum \& Noelli (2020).

As mulheres dominaram a produção das cerâmicas Tupiniquim e, posteriormente, da Cerâmica Paulista. Os homens prevaleceram na produção em Portugal e, como vimos acima, produzindo telhas, tijolos e vasilhas em alguns núcleos coloniais de São Paulo. Em todos os contextos, a formação ocorria nas comunidades de práticas familiares (Fernandes F. 1975; Fernandes I. 2012; Scheuer 1976).

Em Portugal, o trabalho era preferencialmente residencial, com funções hierarquizadas, normalmente dirigidas pelo ceramista mais experiente e dono dos meios de produção. A principal função era "levantar" a vasilha na roda de oleiro, geralmente feita pelo proprietário, que era servido por pessoas da família e empregadas nas diversas especialidades, desde a coleta do barro até a decoração (eventualmente feita por mulheres). No caso das cerâmicas Tupiniquim e paulista, a produção era residencial e uma única mulher executava todas as etapas de produção, mas eventualmente a localização das jazidas, a extração e o transporte do barro poderiam ser de quaisquer pessoas da sua família.

As cerâmicas portuguesas eram fabricadas para uso familiar e para as redes de comércio locais e regionais. A produção Tupiniquim era autossustentada e residencial, para a família nuclear, eventualmente colaborativa no âmbito da família extensa. A Cerâmica Paulista seguiu este padrão Tupiniquim até o século XVIII, quando passou a ser comercializada para abastecer os núcleos urbanos em crescimento e, eventualmente, as plantations.

A atividade em Portugal era regulamentada pelo poder real (e depois republicano), que autorizava, fiscalizava e recolhia impostos sobre a produção cerâmica. As cerâmicas Tupiniquim e paulista tinham a manutenção da atividade baseada na confiança e na estética das vasilhas, como condicionantes do uso residencial, posteriormente, extra residencial para fins comerciais. A cobrança de impostos sobre a produção parece começar apenas no século XVIII, sendo um tema a ser investigado em São Paulo (cf. Rabello 1977).

\begin{tabular}{|c|c|c|c|}
\hline Contexto de produção & Tupiniquim & Cerâmica portuguesa & Cerâmica Paulista \\
\hline Gênero dominante & Feminina & Masculina & Feminina \\
\hline Estrutura de trabalho & Familiar & Familiar & Familiar \\
\hline \multirow{3}{*}{ Formação } & Doméstica & Doméstica & Doméstica \\
\hline & Linhagem feminina & Linhagem masculina & Linhagem feminina \\
\hline & Comunidade de práticas & Comunidade de práticas & Comunidade de práticas \\
\hline \multirow[b]{2}{*}{$\begin{array}{l}\text { Organização do trabalho } \\
\text { e cadeia operatória }\end{array}$} & Generalista & Hierarquizada & Generalista \\
\hline & $\begin{array}{l}\text { Domina todas as etapas, } \\
\text { eventual auxílio na } \\
\text { extração e transporte de } \\
\text { matéria-prima }\end{array}$ & Tarefas especializadas & $\begin{array}{l}\text { Domina todas as etapas, } \\
\text { eventual auxílio na } \\
\text { extração e transporte de } \\
\text { matéria-prima }\end{array}$ \\
\hline Distribuição & Local & Local/Regional & Local/Regional \\
\hline Atividade & Desregulamentada & Regulamentada/estatal & Desregulamentada \\
\hline Permissão & - & Alvará/Exame Público & $\begin{array}{l}\text { Confiança no produto e } \\
\text { estética }\end{array}$ \\
\hline
\end{tabular}

Quadro 1: Contexto de produção. 
Comunidades de mulheres ceramistas e a longa trajetória de itinerância da cerâmica paulista

R. Museu Arq. Etn., 34: 132-153, 2020.

\section{Processo de produção cerâmica}

Era estruturalmente semelhante nos três conjuntos vasilhas, como mostramos no Quadro 2:

Em Portugal, a preparação do barro possuía várias etapas, sendo exclusivamente masculina. No caso das Tupiniquim e da Cerâmica Paulista, as mulheres realizavam essas tarefas, eventualmente sendo auxiliadas pelos homens na extração e transporte.

Os homens levantavam as vasilhas em Portugal, sobre a roda baixa ou no torno. Os dois aparelhos não foram adotados pelas Tupiniquim, nem posteriormente na Cerâmica Paulista, sendo usual a prática de moldar a base e acordelar as paredes até o lábio (algumas classes funcionais poderiam ter a base acordelada).
Na metade norte de Portugal as vasilhas eram enegrecidas com a pigmentação natural da argila. Era uma técnica não conhecida no período pré-colonial pelas Tupiniquim. Porém, as evidências indicam que uma da Cerâmica Paulista foi tingida com corantes vegetais pretos após a primeira queima, com um sumo das cascas de aroeira (corneíba) (Schinus terebinthifolius Raddi) ou de jacatirão (kuipeúna) (Tibouchina mutabilis Cogn.), uma técnica utilizada até hoje (Nascimento 1986; Scheuer 1976), para cobrir a paleta de cores avermelhadas, marrons e cremes das argilas regionais (Fig. 4). Os processos pós-deposicionais no contexto arqueológico levariam as alterações químicas modificando de preta para tons cinzas, como acontece em Portugal com a cerâmica preta (Costa 2014).

\begin{tabular}{|l|l|l|l|}
\hline \multicolumn{1}{|c|}{ Atividade } & \multicolumn{1}{|c|}{ Tupiniquim } & \multicolumn{1}{c|}{ Cerâmica Comum Portuguesa } & \multicolumn{1}{c|}{ Cerâmica Paulista } \\
\hline Preparação do barro & Feminina & Masculina & Feminina \\
\hline \multirow{2}{*}{ Levantar a peça } & Modelado/acordelado & Roda Baixa e Torno & Modelado/acordelado \\
\cline { 2 - 5 } & Feminina & Masculina & Feminina \\
\hline Pigmentação Preta & Inexistente & Argila & Fegetal \\
\hline Polir/brunir & Feminina & Masculina/Feminina & Feminina \\
\hline Aguada & Feminina & Masculina & \\
\hline $\begin{array}{l}\text { Decoração: } \\
\text { Linha incisa } \\
\text { Asa, alça, bico } \\
\text { Cinta/cordão de barro } \\
\text { Pintura }\end{array}$ & Feminina & Masculina/Feminina & Feminina \\
\hline Queima & Ar livre & Forno/ar livre & \\
\hline Resina vegetal & Presente & Masculina & Forno/ar livre \\
\hline & Feminina & Ausente & Feminina \\
\hline Vasilha decorada & Pintada não vai ao fogo & Geralmente não vai ao fogo & Presente \\
\hline
\end{tabular}

Quadro 2: Cadeia operatória.
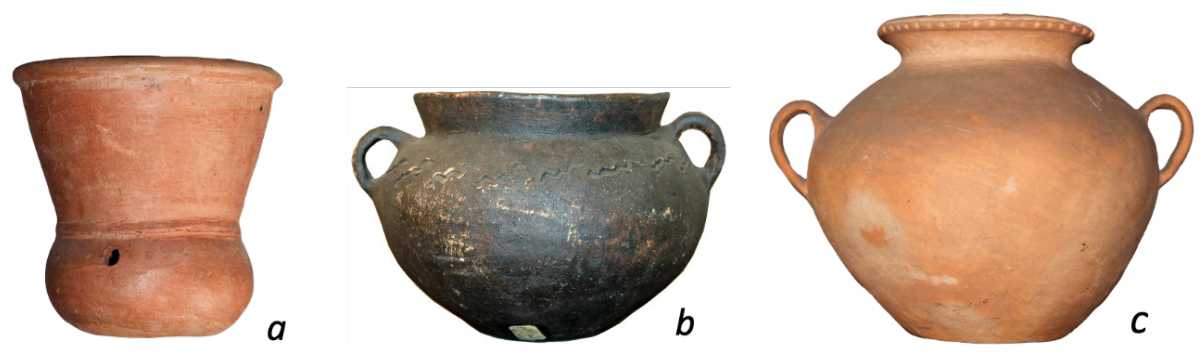

Fig. 4. Frigideira tingida com preto. B: British Museum, Londres. em contraste com os pigmentos naturais do com cuscuzeiro vermelho e boião creme. A e C: Museu Casa do Barão, São Vicente, SP.

Fotos: A e C: Francisco Silva Noelli; B: cortesia do British Museum. 
Enquanto a peça tinha a contextura do couro, as mulheres portuguesas eventualmente bruniam e/ou poliam. Na sequência, para vedar e uniformizar a superfície, a peça recebia uma aguada em ambos os lados da parede. Esta ordem da cadeia operatória era semelhante nas cerâmicas Tupiniquim e paulista. A aguada, também chamada de barbotina no Brasil, tinha densidades variadas, conforme a necessidade de preenchimento da porosidade e, também, da pigmentação da vasilha. As mulheres faziam a decoração nos dois lados do Atlântico e, eventualmente, os homens em Portugal.

A superfície interna é lisa nos três conjuntos cerâmicos; no caso Tupiniquim, algumas classes funcionais recebiam pintura interna de linhas e pontos vermelhos e pretos sobre fundo branco (raramente creme), especialmente os pratos coletivos. A superfície externa lisa predomina na cerâmica comum portuguesa, mas possui várias possibilidades de combinações decorativas, recebendo, por exemplo, cordões ou cintas de barro, linhas incisas curvilíneas e diagonais, caneluras, impressões e pintura com motivos florais (Bugalhão \& Coelho 2017). A cerâmica Tupiniquim tinha várias possibilidades de superfície externa, com tratamentos de superfície usados de forma isolada ou composta, com os seguintes tipos dependendo da classe funcional: lisa, ungulada, corrugada, ponteada, incisa, espatulada, escovada e pintada com motivos geométricos. Três cores eram as principais, obtidas com os seguintes pigmentos minerais: (1) taguá, vermelho, um composto de óxido de ferro; (2) tabatinga, branco, composto por caulim; e (3) preto, um composto de óxido de manganês (Sallum et al. 2018).

As palavras Tupiniquim, tagoâ e tobâtínga foram registradas no século XVI pelo missionário José de Anchieta (1595: 14v), termos mantidos posteriormente na Língua Geral Paulista e na própria Cerâmica Paulista. Esta cerâmica tem as superfícies predominantemente lisas na maioria das classes funcionais. Algumas classes poderiam ter composições com motivos diversos, total ou parcialmente: as vasilhas pintadas desapareceram após perderem gradativamente espaço na segunda metade do século XX, pela dificuldade de acesso aos pigmentos minerais devido às questões fundiárias (Scheuer 1976).

A Cerâmica Paulista poderia ter a superfície externa lisa, mas algumas seriam total ou parcialmente escovadas, estocadas ou corrugadas. As decorações com linhas incisas onduladas ou diagonais, ou cintas e cordões de barro decoradas no estilo português eram sobrepostas nas superfícies lisas. As alças, asas e bicos eram inexistentes na Tupiniquim (Fig. 5), mas eram usuais na cerâmica comum portuguesa e na Cerâmica Paulista. Até o momento, há escassos registros arqueológicos Tupiniquim de bicos, asas e alças fora dos núcleos coloniais. Parece que havia a opção de se apropriar de tais atributos, porém fora dos padrões portugueses, sugerindo que a ceramista não pertenceria a uma comunidade de práticas coloniais.

A queima da cerâmica à céu aberto ocorria nas três práticas: (1) Portugal: queimava-se grandes quantidades de vasilhas à céu aberto na soenga, usada até o presente; (2) Tupiniquim: poucas vasilhas por queima; e (3) Cerâmica Paulista: semelhante a soenga, quando não usava o forno. A queima no forno é usual entre as cerâmicas portuguesas e paulistas.

Em algumas classes funcionais das cerâmicas Tupiniquim se usava revestimento ("envernizamento") com resina vegetal. Mas em Portugal e na Cerâmica Paulista ela não era empregada. A sua matéria prima era a árvore almecegueira, ou breu branco, chamada na língua indígena de yayra ysy (Protium heptaphylum (Aubl.) Marchand) e, nas áreas mais elevadas sobre a Serra Geral, se poderia usar a kuri 'í (Araucaria angustifolia (Bertol.) Kuntze). Depois da queima a resina era passada aquecida em estado líquido, para selar a superfície, concluir a impermeabilização e deixar um acabamento envernizado internamente e sobre as superfícies pintadas.

As Tupiniquim não usavam sobre o fogo as vasilhas envernizadas e pintadas, salvo os camucim que eram levemente aquecidos com braseiro ao redor da base para fermentar e armazenar o cauim. As demais poderiam ir ao fogo, especialmente para processar alimentos e, eventualmente, as maiores para servir e manter aquecida a refeição. As vasilhas pintadas portuguesas e paulistas não iam ao fogo. 


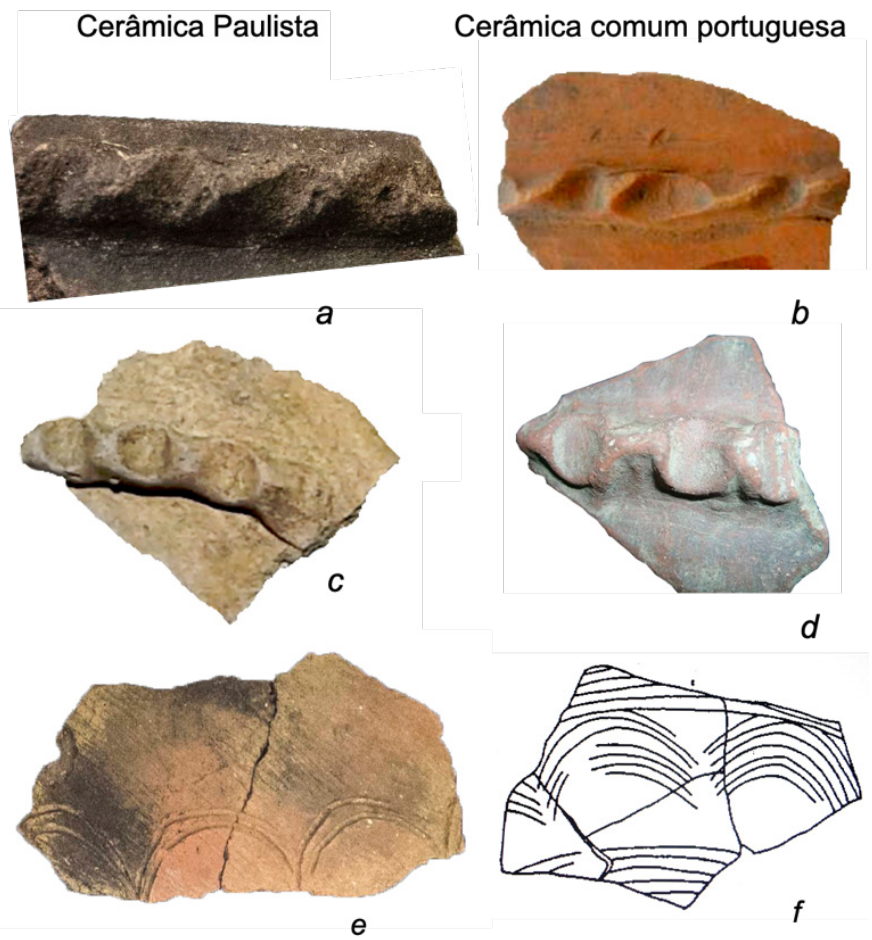

Fig. 5. Comparação dos tratamentos de superfície entre Cerâmica Paulista e cerâmica comum portuguesa. A: cordão de barro do sítio "Ruínas do Abarebebê" (Peruíbe, SP; acervo MAE-USP, foto Marianne Sallum); B: cordão de barro cerâmica medieval (Nazaré 2013); C: cordão de barro de Antonina, PR (foto in situ de F. S. Noelli); D: cordão de barro do Museu de Évora (sem data); E: motivos incisos do sítio "Ruínas do Abarebebê" (Peruíbe, SP; acervo MAE-USP, foto de Marianne Sallum); F: motivos incisos medievais (Terras Novas) (Ferreira 1998).

\section{Linguagem}

A linguagem é um tema de grande interesse para compreender os diversos aspectos da Cerâmica Paulista. Foi, certamente, o elemento central da sociabilidade e da articulação entre práticas indígenas e europeias, passando paulatinamente do bilinguismo para a Língua Geral Paulista (Leite 2013) e, por fim, para o português ("brasileiro" e "caipira"). Essa itinerância da linguagem da materialidade provavelmente teve dois fluxos principais: (1) deriva genética a partir da área de São Vicente-Cananéia, de onde foi se espalhando de modo exponencial, acompanhando a fundação de novos assentamentos coloniais; e (2) posteriormente, com a chegada de forasteiros, outras práticas culturais e linguagens foram articuladas e espalhadas dentro das redes. Assim como as Tupiniquim se apropriaram da tecnologia e das linguagens portuguesas, os portugueses fizeram o mesmo, como se nota na língua portuguesa falada no Brasil. Contudo, trata-se de um tema inteiramente aberto à pesquisa. Como ponto de partida para orientar a busca nas fontes escritas e interpretar os registros arqueológicos, mostramos na Quadro 3 duas amostras taxonômicas, de São Paulo, Paraná (Scheuer 1967, 1976, 1982) e Portugal (Bugalhão \& Coelho 2017; Fernandes 2012). Elas aportam subsídios para comparar a língua portuguesa em São Paulo com as extintas línguas Tupiniquim e Geral Paulista, que precisam ser igualmente investigadas. 
Francisco Silva Noelli

Marianne Sallum

\begin{tabular}{|c|c|c|c|}
\hline Cerâmica Paulista & Função & $\begin{array}{c}\text { Cerâmica comum } \\
\text { portuguesa }\end{array}$ & Função \\
\hline lepósito & Armazenar líquido & Cântaro, talha, pote, bilha & Armazenar líquido \\
\hline Pichorra & Bule de café & $\begin{array}{c}\text { Infusa, Jarra, Jarrinha, } \\
\text { Pichel }\end{array}$ & Para servir líquido \\
\hline & $\begin{array}{c}\text { Armazenar líquidos, } \\
\text { sal etc. }\end{array}$ & Boião, Potinho & $\begin{array}{c}\text { Armazenar e servir alimentos } \\
\text { semi-sólidos à mesa }\end{array}$ \\
\hline & Transportar líquido & $\begin{array}{l}\text { Cantil, cantimplora, } \\
\text { gorgoleta }\end{array}$ & Transportar líquido \\
\hline Cusc & Cozinhar milho e arroz & Cuscuzeiro & Cozinhar semolina \\
\hline Panela de mutirão & $\begin{array}{l}\text { Grande capacidade } \\
\text { para cozinhar }\end{array}$ & $\begin{array}{l}\text { Panela, asado, caldeirão, } \\
\text { púcara }\end{array}$ & Cozinhar \\
\hline & Cozinhar & Panela, asado, púcara & Cozinhar \\
\hline & Fritar & $\begin{array}{c}\text { Frigideira, caçarola, caçoila, } \\
\text { sertã }\end{array}$ & Fritar \\
\hline Frigideira & $\begin{array}{c}\text { "esquentar" rolos de } \\
\text { tabaco }\end{array}$ & & \\
\hline & Torrar & & \\
\hline Prato & Armazenar e servir & Prato, pratel, trincho & $\begin{array}{c}\text { Servir e, no caso dos tamanhos } \\
\text { maiores, uso coletivo }\end{array}$ \\
\hline
\end{tabular}

Quadro 3: Linguagem da Cerâmica Paulista e portuguesa.

Legenda: a) Pote, produzido por Gonilda Bela Cruz de Lima (Encapoeirado, Apiaí); b) Acervo do Museu Casa do Barão (São Vicente), c) Cuscuzeiro, produzido por Benedita Dias (Juquiá); d) Acervo do Museu Estrada de Ferro Sorocabana; e) Coleção Marianne Sallum (Jairê/Iguape); f) fragmento arqueológico do sítio Ruínas do Aberebebê, acervo MAE-USP, reconstrução Carolina Guedes. Fotos: Francisco S. Noelli (menos Apiaí, de autor desconhecido). 


\section{Forma das vasilhas}

As cerâmicas portuguesas e paulista possuem mais uniformidade morfológica e taxonômica entre si, diferenciando-se da cerâmica Tupiniquim. A maioria apresenta paredes com espessuras finas a médias (entre 0,4 e $1,5 \mathrm{~cm}$ ), tanto nas vasilhas que vão ao fogo, como naquelas usadas para servir e armazenar alimentos e líquidos. Os corpos apresentam formas arredondadas, ovoides, elípticas e troncocônicas com contornos complexos, com bases planas ou levemente arredondadas.

Em termos gerais, as vasilhas da Cerâmica Paulista possuem poucas formas com abertura restringida em comparação com a cerâmica comum portuguesa. Em Portugal, a maioria das restringidas tinha função de armazenar ou transportar líquidos, recebendo diversos nomes conforme a função: bilha, talha, cântaro, infusa, cantil, botija e pote (com vários sinônimos dependendo da funcionalidade). Estas vasilhas tinham um amplo repertório estético, com variabilidade de atributos e composições decorativas ainda não encontradas em São Paulo. O itinerário das morfologias associadas ao consumo e ao que se produzia em termos alimentares ainda é um tema inteiramente aberto à pesquisa, dependente de informações por encontrar nos registros arqueológicos e históricos, uma vez que a trajetória dos conjuntos de vasilhas que chegaram ao século XX é desconhecido. Por exemplo, as maiores vasilhas para armazenar líquidos, equivalentes aos cântaros e talhas, parecem restritas aos potes para água, não havendo ainda notícia sobre outros conteúdos líquidos.

Daí surgem problemas sobre o consumo de vinho, cachaça, azeite, vinagre. Se consumidos, onde eram estocados? E outros problemas sobre o cultivo e processamento de uvas e oliveiras, mas sabemos que a cana foi mais comum, sendo manejada pelas populações da costa, desde o começo do século XVI. Em 1585, já se cultivava uvas em Piratininga, mas ainda não se havia resolvido onde armazenar o vinho, pois não haviam encontrado a madeira certa para fazer barris. Quando esteve no assentamento, Cardim
(1937: 94) relatou que "tem trabalho em o conservar, porque em madeira fura-lhe a broca logo, e talhas de barro não nas têm; porém buscam seus remédios, e vão continuando, e cedo haverá muitos vinhos".

As formas paulistas têm o diâmetro da abertura proporcionalmente maior que as portuguesas, quando se compara individualmente as vasilhas no quesito função. Mas ainda temos dúvidas se foi resultado de escolha estética, tecnológica ou hábitos de consumo. A estética poderia resultar do fato da maioria das vasilhas Tupiniquim pré-coloniais, salvo as panelas, não serem restringidas? A tecnologia seria resultado da prática do acordelado, considerando que formas restringidas são comuns ao torno, ou seria uma decisão tecnológica baseada na estética? O consumo é um tema de mais complexa definição, envolvendo necessariamente o conhecimento das práticas Tupiniquim, para se tentar uma definição mais precisa. Mas trata-se de outro tema inteiramente desconhecido e por ser explorado.

As bordas das vasilhas de armazenar e servir são extrovertidas com inclinações variadas, geralmente o prolongamento do pescoço. Nas panelas são diretas ou sutilmente extrovertidas. Nas frigideiras, assadeiras e torradeiras são introvertidas, enquanto nos pratos e tigelas são extrovertidas.

A base é um item que mudou radicalmente na Cerâmica Paulista. A cerâmica Tupiniquim pré-colonial tinha a maioria de suas vasilhas com base cônica e arredondada, mas apenas uma classe funcional com base plana: as vasilhas quadrangulares, ovaladas e triangulares, com paredes de até $2 \mathrm{~cm}$ de espessura, com a borda reforçada externamente e pintadas internamente. Na Cerâmica Paulista predominam bases planas, evidente influência portuguesa, mas eventualmente as panelas têm bases arredondadas ou levemente cônicas.

As formas ainda precisam ser definidas, sendo necessário ampliar a amostragem e a base estatística para aumentar a confiabilidade das comparações. Conseguimos avançar no caso das panelas: elas têm estabilidade morfológica na nossa amostra, podendo dividi-la em dois conjuntos conforme o tamanho: (1) familiar, 
com dimensões e volume proporcional ao número de indivíduos; ou (2) comunitário, de grandes dimensões para uso em festas e como parte da reciprocidade de um trabalho de mutirão. Elas têm em comum com as panelas portuguesas um pescoço relativamente restringido, direto, sem reforço na borda, como não ocorria nas panelas Tupiniquim.

Os jarros, púcaros, cântaros ou talhas no contexto português, são usados para conservar e transportar líquidos. Na Cerâmica Paulista há o depósito, boião e o pote, que possuem morfologia e função similares, corpo ovoide alongado ou globular, base plana e duas alças, ou asas. As frigideiras aparecem nas cerâmicas paulista e portuguesa. Elas normalmente possuem mais de uma função, dependendo do tamanho e de algumas especificidades tecnológicas, servindo para esquentar fumo em rolo (vasilhas menores), e fritar alimentos (vasilhas maiores), mantendo as características morfológicas. Apresentam, comumente, paredes curvadas com bordas contínuas ou tronco-cônicas, cabos e asas em posições opostas. Em alguns casos, possuem tratamento ondulado nas asas e as paredes polidas e tingidas de preto. Já os cabos são formados por rolos duplos e, por vezes, achatados. As asas são curvilíneas e, em alguns casos, possuem decoração ondulada. $\mathrm{O}$ torrador ocorre nas cerâmicas Tupiniquim e paulista para processar farinha de mandioca e a torrefação dos grãos de café, mas não na cerâmica portuguesa (Fig. 6).
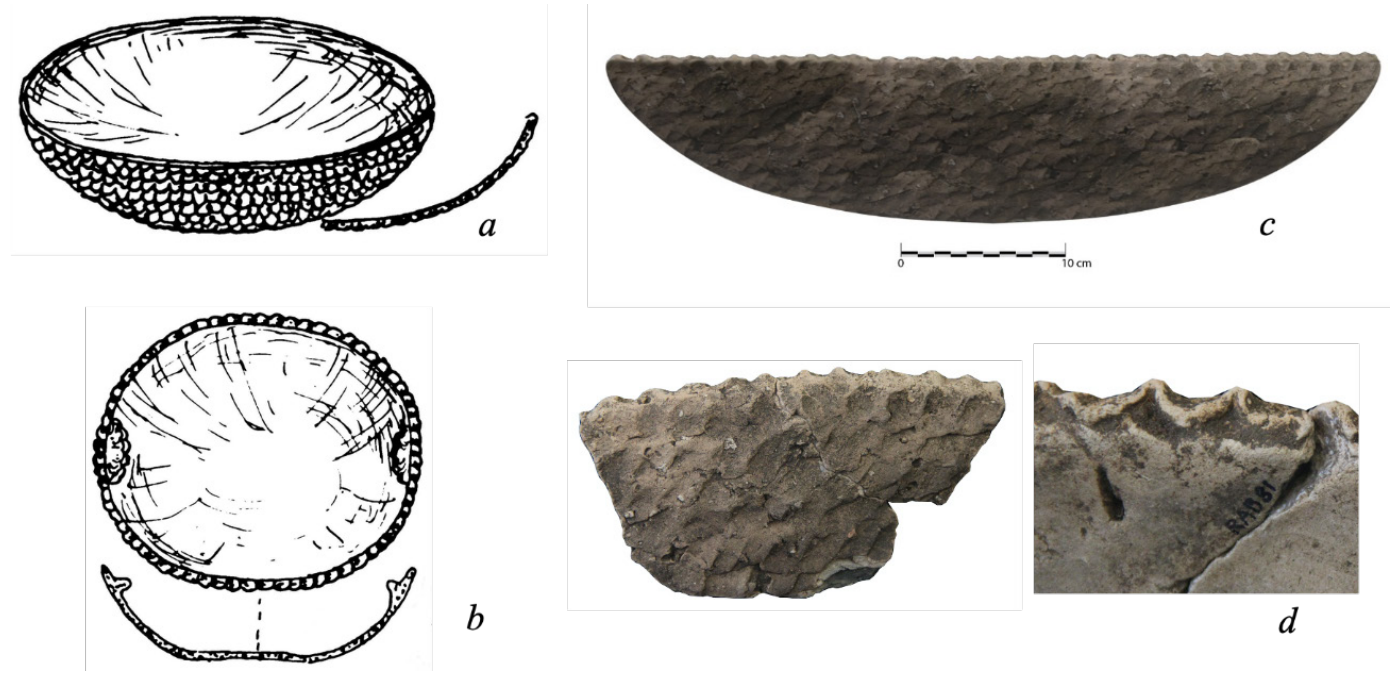

Fig. 6. A, B: vasilha registrada próxima de Curitiba, por Tiburtius (1968-1969); C, D: reconstrução gráfica e fragmentos do torrador do sítio "Ruínas do Abarebebê". Foto: Marianne Sallum; Reconstrução: Carolina Guedes.

\section{Conclusão}

O itinerário da Cerâmica Paulista percorreu múltiplos caminhos até o presente. Percebemos que a produção manteve basicamente as formas, com algumas variações de tratamentos de superfície locais e regionais, decorrentes de novas conformações sociais e significados, especialmente a partir do século XVIII, com a intensificação do comércio, novos ingredientes e a presença de mais europeus e africanes.
As informações de Scheuer e Haydée Nascimento mostram os significados das décadas de 1960 e 1970, que podem ser atualizados com pesquisas mais recentes (Calaresi 2014; Cerávolo 1988; Lima 2007; Magrini 2019; Noelli \& Sallum 2019; Souza 2015; Waldeck 2014). O comum entre essas pesquisas é a identificação da continuidade na transmissão de conhecimentos entre comunidades de mulheres inseridas "dentro de suas próprias visões de mundo culturalmente 
definidas" (Panich 2020), elaboradas em lugares e momentos históricos particulares. Na segunda metade do século 20, as ceramistas adotaram uma perspectiva mais livre em relação as formas tradicionais, buscando atender demandas do mercado do artesanato para benefício econômico (Magrini, 2019).

O consumo possui distinções mais evidentes, conforme o contexto.

Nas comunidades de prática, a culinária tinha como base os vegetais cultivados pelo manejo agroflorestal, adotando, eventualmente, produtos e práticas introduzidos por europeus e africanes. Temos em alguns locais a produção de trigo, uva e marmelo. As proteínas variavam proporcionalmente em relação a configuração ecológica local do assentamento, havendo caça em todos os lugares, mas restrições de fauna aquática dependendo do acesso aos cursos d'água. A criação de animais também foi uma prática introduzida pelos europeus, mas nem todas as comunidades a adotaram ou conseguiam mantê-la.

Nos locais que adquiriam vasilhas por troca ou compra, a dieta poderia variar mais, especialmente onde chegavam pessoas com conhecimentos culinários diferentes do Tupiniquim. Isso ocorria especialmente nos núcleos urbanos e nas plantations, os locais mais integrados aos circuitos comerciais. O consumo de doces cozidos foi outra prática apropriada dos europeus e transformada, começando com o marmelo e o açúcar, duas das primeiras produções coloniais a serem exportadas. Nestes locais há informações sobre diversos equipamentos de cozinha e de serviço importados que coexistiam com a Cerâmica Paulista (Bruno 2010; Machado 2013).

Este cenário de gradativa diversificação da dieta resultou na culinária caipira (Dória \& Bastos 2018), composta por técnicas, práticas e ingredientes indígenas, africanes e europeias.
A Cerâmica Paulista articulou conhecimento de gerações de mulheres, conectadas entre si pela tecnologia, prática, consumo, significados e memórias. A sua persistência englobou tanto a continuidade das práticas, como os diversos significados e atributos incorporados ao longo do tempo. Quando pensamos nos "objetos em movimento", podemos seguir a perspectiva de Appadurai (1986), "as coisas não têm significados além daqueles que thes dotam as transações, atribuições e motivações humanas". O argumento é: para entender as coisas, precisamos seguir as próprias coisas, os seus significados inscritos em suas formas, usos, trajetórias.

\section{Agradecimentos}

Ao Conselho Nacional de Desenvolvimento Científico e Tecnológico (CNPq, processo 150312/2018-0) e à Fundação de Amparo à Pesquisa do Estado de São Paulo (á FAPESP, processo no 2019/17868-0 e 2019/18664-9). Agradecimento especial à mestra ceramista Dona Dita (Benedita Dias) de Iguape, e Professora Fátima Pires, do município de Peruíbe. A Carmelita Moraes, pela autorização das fotos de Plácido de Campos Júnior. Aos amigues Steve Silliman, Lúcio Menezes Ferreira, Ângela Buarque, Ana Suelly Cabral, Marisa Coutinho Afonso, Carlos Fabião, Tânia Casimiro, Carolina Guedes, Marcos André de Souza, Mercedes Okumura, Camila Agostini, Astolfo Araujo, Plácido Cali, Ângelo A. Corrêa, Márcia Hattori e Hélio Rosa de Miranda. Ao Museu de Arqueologia e Etnologia da Universidade de São Paulo, especialmente Cristina Demartini, Dária Barreto, Paulo Jacob e Regivaldo L. da Silva. Ao UNIARQ pelo acolhimento na Universidade de Lisboa, onde este artigo foi escrito. Aos pareceristas anônimos pelas sugestões. 
NOELLI, F.S.; SALLUM, M. Communities of women ceramicists and the long path of itinerancy of Paulistaware in São Paulo. R. Museu Arq. Etn. 34: 132-153, 2020.

\begin{abstract}
The Paulistaware resulted from the connection between generations of women potters, linked together by technology, practice, consumption, meanings, and memories. It was initially produced by the tupiniquins, in an alliance with the Portuguese in the São Vicente area.These practices continue through several generations of women, including those who came from abroad. In the context of these relationships, materialities and foods were used, appropriated and transformed, through choices that intertwined old technologies with novelties and cultural and identity changes. The analysis of whole vessels, fragments, and published data shows that the production of Paulistaware start in the 16th century, with some variations in morphology, attributes, and decoration over time. The persistence of the communities of practice led to ways of making and using ceramic vessels, shaping values, and social relations that defined the Paulista identity.
\end{abstract}

Keywords: Archaeology, Colonial pottery, Gender, Tupi, Colonialism

\title{
Referências bibliográficas
}

Agostini, C. 2010. Panelas e paneleiras de São Sebastião: um núcleo produtor e a dinâmica social e simbólica de sua produção nos séculos XIX e XX. Vestígios: Revista Latino-Americana de Arqueologia Histórica 4(2): 127-144.

Almeida Prado, J.F. 1961. São Vicente e as capitanias do Sul do Brasil: as origens (1501-1531). Companhia Editora Nacional, São Paulo.

Almeida, F.O. 2015. A arqueologia dos fermentados: a etílica história dos Tupi-Guarani. Estudos Avançados 29(83): 87-118.

Anchieta, J. 1595. Arte de gramática da lingoa mais vsada na costa do Brasil. António de Mariz, Coimbra.

Anchieta, J. 1933. Padre Diogo Jácome. In: Anchieta, J. Cartas, informações, fragmentos históricos e sermões. Civilização Brasileira, Rio de Janeiro, 482-484.

Anchieta, J. 1958. Carta ao padre Diego Laynes. Roma, São Vicente, 1 de junho de 1560. Monumenta Brasiliae 3: 246-269.
Anônimo. 1956. Extrato do alvará da mercê à igreja de São Vicente, Capitania de São Vicente. Lisboa, 20 de fevereiro de 1553. In: Cortesão, J. (Ed). Pauliceae Lusitana Monumenta Histórica, Real Gabinete Português de Leitura no Rio de Janeiro, Lisboa, 1 (1494-1600), partes V-VIII, 337.

Anônimo. 1968. Carta. Santos, 13 de maio de 1548. In: Stol. E. Um dos primeiros documentos sobre o engenho dos Schetz em São Vicente. Revista de História 37(76): 407-420.

Appadurai, A. 1986. Introduction: Commodities and the Politics of Value. In: Appadurai, A. The Social Life of Things: Commodities in Cultural Perspective. Cambridge: Cambridge University Press. 3-63.

Brancante, E. 1981. O Brasil e a cerâmica antiga. Lythographica Ypiranga, São Paulo.

Brochado, J.P. 1991. What did the Tupinambá cook in their vessels? A humble contribution to ethnographic analogy. Revista de Arqueologia 6: 40-88. 
Comunidades de mulheres ceramistas e a longa trajetória de itinerância da cerâmica paulista

R. Museu Arq. Etn., 34: 132-153, 2020.

Bruno, E.S. 2001. Equipamentos, Usos e Costumes da Casa Brasileira, 5 vols. Editora da Universidade de São Paulo, São Paulo.

Bugalhão, J.; Coelho, I. 2017. Cerâmica moderna de Lisboa: proposta tipológica. In: Caessa, A. et al. (Eds.). I Encontro de Arqueologia de Lisboa: uma cidade em escavação. CAL/DPC/DMC/CML, Lisboa, 106-145.

Calaresi, A.C.M.A. 2014. Argila: matéria-prima para cerâmica popular - Três casos: Rio Real (BA), Apiaí (SP) e Taubaté (SP). Tese de doutorado. Universidade de São Paulo, São Paulo.

Câmara Municipal de São Paulo. 1915. Conserto que fizeram os oficiais da câmara com Fernão Dalves para fazer o pelourinho. São Paulo, 23 de maio de 1610. Atas da Câmara Municipal de São Paulo 2: 268-269.

Câmara Municipal de São Paulo. 1967. Obrigação de Cristóvão Gonçalvez para fazer telhas para esta vila. São Paulo do Campo, 6 de março de 1575. Atas da Câmara Municipal de São Paulo 1(2): 66-66.

Cardim, F. 1937. Tratado da terra e gente do Brasil. Companhia Editora Nacional, São Paulo.

Carneiro da Cunha. M.; Viveiros de Castro, E. 1985. Vingança e temporalidade: os Tupinambá. Journal de la Société des Américanistes 71: 191-208.

Cerávolo, M.V.N. 1988. Cerâmica de Apiaí: momentos de uma pesquisa em arte popular. Cerâmica 34(217): 15 .

Cipolla, C. 2017. Indigenous people and foreign objects: rethinking consumption in American archaeology. In: Cipolla, C. (Ed). Foreign objects: rethinking indigenous consumption in American Archaeology. University of Arizona Press, Tucson, 3-25.

Corrêa, A. 2014. Pindorama de Mboia e Iakaré: continuidade e mudança na trajetória das populações Tupi. Tese de doutorado. Universidade de São Paulo, São Paulo.
Costa, B. 2014. A Cerâmica Preta do Mosteiro de São João de Tarouca. Dissertação de mestrado. Universidade Nova de Lisboa, Lisboa.

Costa, D. 1556. Carta ao Rei. Salvador, 03 de abril de 1555. In: Cortesão, J. (Ed). Pauliceae Lusitana Monumenta Histórica, Real Gabinete Português de Leitura no Rio de Janeiro, Lisboa, 1 (1494-1600), partes V-VIII, 338-343.

Dória, C.A., Bastos, M.C. 2018. A culinária caipira da Paulistânia. Três estrelas, São Paulo.

Fernandes, F. 1975. Estudos de etnologia e outros ensaios. Vozes, Petrópolis.

Fernandes, I. 2012. A loiça preta em Portugal: estudo histórico, modos de fazer e de usar. Tese de doutorado. Universidade do Minho, Braga.

Ferreira, M.M.N. 1998. As cerâmicas medievais/ modernas do Abrigo da Pena d’Água (Torres Novas). Revista Portuguesa de Arqueologia 1(2): 97-106.

Goldman, M. 2017. Contradiscursos Afroindígenas sobre Mistura, Sincretismo e Mestiçagem Estudos Etnográficos. Revista de Antropologia da UFScar, 9(2): 11-20.

Gosselain, E.M. 1876. Documents authentiques et inédits pour servir à l'histoire de la marine Normande et $d u$ commerce rouennais pedant les $X V I^{\mathrm{e}}$ et $X V I I^{\mathrm{e}}$ siégles. Imprimerie de Henry Boissel, Rouen, 37-40.

Hayes, K. 2011. Occulting the past. Conceptualizing forgetting in the history and archaeology of Sylvester Manor. Archaeological Dialogues, 18(2): 197-221.

Jácome, D. 1956. Carta de São Vicente, junho de 1551. In: Leite, S. (Ed). Monumenta Brasilie. ARSI, Roma, 1, 238-247.

Jones, S. 1997. The archaeology of ethnicity: constructing identities in the past and present. Routledge, London. 
Joyce, R.D.; Gillespie, S.D. 2015. Making things out of objects that move. In: Joyce, R.D.; Gillespie, S.D. (Eds). Things in motion: objects itineraries in anthropological practice. School for Advanced Research Press, New Mexico, 3-21.

Lagrou, E. 2013. No caminho da miçanga: arte e alteridade entre os ameríndios. Enfoques - Revista dos Alunos do PPGSA-UFRJ 12(1): 18-49.

Lagrou, E. 2016. No caminho da miçanga: um mundo que se faz de contas. Museu do Índio, Rio Janeiro, 10-15. Catálogo de exposição.

Leite, F. 2013. A língua geral paulista e o "vocabulário elementar da língua geral brasílica”. Dissertação de mestrado. Universidade Estadual de Campinas, Campinas.

Lima, M.R.M. 2007. A fotografia como instrumento da documentação e preservação da memória: arte e sobrevivência no Alto Vale do Ribeira. Dissertação de mestrado. Pontifícia Universidade Católica, São Paulo.

Machado, A. 2013. Vida e morte do bandeirante. Senado Federal, Brasília.

Magrini, A. 2019. Lá no Alto, o barro é encantado: a cerâmica do Alto Vale do Ribeira. Dissertação de mestrado. Universidade Estadual Paulista, São Paulo.

Monteiro, J.M., 2001. Tupis, Tapuias e Historiadores: Estudos de História Indígena e do Indigenismo. Tese de livre-docência. Universidade Estadual de Campinas, Campinas.

Morales, W. 2001. A cerâmica "neo-brasileira" nas terras paulistas: um estudo sobre as possibilidades de identificação cultural através dos vestígios materiais na vila de Jundiaí do século XVIII. Revista do Museu de Arqueologia e Etnologia 11: 165-187.

Munsberg, S.E.R. 2018. Dos seiscentos aos oitocentos: estudo da variabilidade estilística da cerâmica durante os processos de construção e reconfiguração das identidades paulistanas. Dissertação de mestrado. Universidade Federal de Minas Gerais, Belo Horizonte.

Nascimento, H. 1986. Cerâmica folclórica em Apiaí. Revista do Arquivo Municipal 186: 45-121.

Nazaré, M. 2013. Cerâmicas medievais de Santa Olaia (Figueira da Foz) depositadas no Museu Municipal Dr. Santos Rocha. Dissertação de mestrado. Universidade de Coimbra, Coimbra.

Noelli, F.S.; Brochado, J.P. 1998. O cauim e as beberagens dos Guarani e Tupinambá: equipamentos, técnicas de preparação e consumo. Revista do Museu de Arqueologia e Enologia 8: 117-128.

Noelli, F.S.; Sallum, M. 2019. A Cerâmica Paulista: cinco séculos de persistência de práticas Tupiniquim em São Paulo e Paraná, Brasil. Mana: Estudos de Antropologia Social 25(3): 701-742. Disponível em: <https://bit.ly/33cZ2sj >. Acesso em: 30/07/2020.

Panich, L.; Allen, R.; Galvan, A. 2018. The archaeology of Native American persistence at mission San José. Journal of California and Great Basin Anthropology 38(1): 11-29.

Panich, L.M. 2020. Narratives of persistence indigenous negotiations of colonialism in Alta and Baja California. The University of Arizona Press, Tucson.

Pazzarelli, F.; Salma, J.F.; Hirose, M.B. 2017. (Contra) Mestiçagens Ameríndias e Afro-ameríndias. Revista de Antropologia da UFSCAR, 9(2):9-10.

Perrone-Moisés, B. 2014. Performed alliances and performative identities Tupinambá in the Kingdom of France. In: Graham, L. (Ed). Performing Indigeneity. Global histories and Contemporary Experiences. University of Nebraska Press, Lincoln, 110-135.

Rabello, E.D.N. 1977. Os Ofícios Mecânicos e artesanatos em São Paulo na segunda metade do século XVIII. Revista de História 112: 575-588. 
Comunidades de mulheres ceramistas e a longa trajetória de itinerância da cerâmica paulista

R. Museu Arq. Etn., 34: 132-153, 2020.

Disponível em: <https:// https://bit.ly/3f9pt4I >. Acesso em: 30/07/2020.

Ribeiro, L.; Jácome, C. 2014. Tupi ou não Tupi? Predação material, ação coletiva e colonialismo no Espírito Santo, Brasil. Boletim do Museu Paraense Emílio Goeldi, Ciências Humanas 9(2): 465-486.

Roddick, A.P.; Stahl, A.B. 2016. Introduction: knowledge in motion. In: Roddick, A.P.; Stahl, A.B. (Eds). Knowledge in motion: constellations of learning across time and place. University of Arizona Press, Tucson, 3-35.

Sagan, C. 1995. The Demon-Haunted World: Science as a Candle in the Dark. Random House, Nova York.

Sallum, M. 2018. Colonialismo e ocupação tupiniquim no litoral sul de São Paulo: uma história de persistência e prática cerâmica. Tese de doutorado. Universidade de São Paulo, São Paulo. Disponível em: <https://bit.ly/3fnoBK1>. Acesso em: 30/07/2020.

Sallum, M.; Noelli, F.S. 2020. An archaeology of colonialism and the persistence of women potters' practices in Brazil: from Tupiniquim to Paulistaware. International Journal of Historical Archaeology. Disponível em: <https://bit. ly/3hNBj64>. Acesso em: 30/07/2020.

Sallum, M. et al. 2018. Estudos de pigmento, pasta e vestígios químicos de cerâmica associados aos povos Tupi do sítio Gramado (Brotas, São Paulo Brasil). Cadernos do Lepaarq 15(30): 191-218. Disponível em: <https://bit.ly/3fgnxao $>$. Acesso em: 30/07/2020.

Santa Cruz, A. 1918. Islario general de todas las islas del mundo. Imprenta del Patronato de Huérfanos de Intendencia e Intervención Militares, Madrid.

Scheuer, H.L. 1967. Estudo de um núcleo de cerâmica popular. Arquivos do Museu Paranaense, Curitiba.
Scheuer, H.L. 1976. Estudo da cerâmica popular do Estado de São Paulo. Conselho Estadual de Cultura, São Paulo.

Scheuer, H.L. 1982. A Tradição da cerâmica popular. Escola de Folclore Livramento, São Paulo.

Sheridan, K. 2018. A century of ceramics: a study of household practices on the eastern pequot reservation. Dissertação de mestrado. University of Massachusetts, Boston.

Silliman, S. 2009. Change and continuity, practice and memory: Native American persistence in colonial New England. American Antiquity 74(2): 211-230.

Silliman, S. 2015. A requiem for hybridity? The problem with Frankenstein, purées, and mules. Journal of Social Archaeology 15(3): 1-22.

Silliman, S. 2020. Colonialism in Historical Archaeology. In: ORSER, C. E. et al. (Eds.). Handbook of Global Historical Archaeology. The Routledge, London.

Sousa, P.L. 1994. Diário da navegação de Pero Lopes de Sousa (1530-1532). In: Guirado, M.C. Relatos do descobrimento do Brasil: as primeiras reportagens. Instituto Piaget, São Paulo.

Sousa, T. 1956. Carta a D. João III. Salvador, 1 de junho de 1553. Monumenta Brasiliae 1: 483-487.

Souza, J. F. 2015. Artesanato e design: identidade e mercado - A produção cerâmica no Vale do Ribeira/SP. Trabalho de conclusão de curso. Universidade de São Paulo, São Paulo.

Staden, H. 1974. Duas viagens ao Brasil. Itatiaia, Belo Horizonte; Edusp, São Paulo.

Tiburtius, G. 1968. Ältere Hauskeramik aus der umgebung von Curitiba, Paraná. Südbrasilien. Anthropos 63/64(1/2): 49-74. 
Viveiros de Castro, E. 1992. O mármore e a murta: sobre a inconstância da alma selvagem. Revista de Antropologia 35: 21-74.

Viveiros de Castro, E. 2004. Exchanging perspectives: the transformation of objects into subjects in Amerindian ontologies. Common Knowledge 10(3): 463-484.

Waldeck, G. 2014. De "luta do barro", "isso do barro", "nesse serviço" à cerâmica de Apiaí. Textos Escolhidos de Cultura e Arte Populares 11(1): 107-128.

Wendrich, W. 2012. Archaeology and apprenticeship: body knowledge, identity, and communities of practice. In: Wendrich, W. (Ed). Archaeology and apprenticeship, body knowledge, identity, and communities of practice. The University of Arizona Press, Tucson, 1-19.

Wenger, E. 1998. Communities of practice: learning, meaning, and identity. Cambridge University Press, Cambridge.

Zanettini, P. 2005. Maloqueiros e seus palácios de barro: o cotidiano doméstico na casa bandeirista. Tese de doutorado. Universidade de São Paulo, São Paulo.

Zanettini, P.; Wichers, C.M. 2009. A cerâmica de produção local/regional em São Paulo colonial. In: Morales, W.F.; Moi, F.P. (Orgs.). Cenários regionais em arqueologia brasileira. Annablume, São Paulo, 311-334. 